EXTENDED REPORT

\title{
Corticosteroid treatment of periorbital haemangioma of infancy: a review of the evidence
}

\author{
T M Ranchod, I J Frieden, D R Fredrick
}

Br J Ophthalmol 2005;89:1134-1138. doi: 10.1136/bjo.2005.070508

See end of article for authors' affiliations

....................

Correspondence to: Douglas R Fredrick, MD, Department of Ophthalmology, University of California, San Francisco, 10 Koret Way, Room K203, San Francisco, CA 941430730, USA; dfred@itsa. ucsf.edu

Accepted for publication 2 May 2005

\begin{abstract}
Aim: To systematically review the literature for corticosteroid treatment of periorbital haemangioma of infancy (HOI) and determine the relative efficacy and safety of oral, topical and intralesional corticosteroids.

Methods: PubMed and the Cochrane Library were queried using keywords, and further articles were obtained by reviewing bibliographies. Inclusion and exclusion criteria were applied to create a subset of literature for analysis.

Results: Systematic review revealed 81 original reports of periorbital $\mathrm{HOl}$ cases treated with steroids. Most studies and case series failed to document refractive error or visual acuity before and after treatment. Of cases meeting inclusion criteria, five patients received topical steroids and 25 patients received intralesional steroids. Patients receiving intralesional injections tended to demonstrate reduced astigmatism at follow up after treatment (21 of 28). The lack of studies with relevant objective ophthalmological end points prevented statistical meta-analysis.

Conclusion: Intralesional injections may reduce refractive error, while the efficacy of topical steroids is unclear. Studies measuring objective ophthalmic data before and after treatment are sparse, and more studies are needed to determine the relative efficacy of different steroids. There are insufficient data to estimate the incidence of steroid side effects in patients treated with steroids for periorbital $\mathrm{HOl}$ or complications of intralesional injections in particular.
\end{abstract}

$\mathrm{H}$ aemangiomas of infancy (HOI) are benign tumours that occur superficially or deep in the dermis and that usually involute spontaneously following a period of proliferation. ${ }^{1}$ Visual impairment most often results from haemangiomas of the eyelids impinging on the visual axis but may also occur when haemangiomas exert pressure on ocular structures. Occlusion by eyelid and other superficial haemangiomas can result in amblyopia, strabismus, or anisometropia because of myopic shifts or associated induced astigmatism. Retro-orbital haemangiomas can induce proptosis. $^{2}$ Although HOI invariably involute, treatment of periocular haemangiomas is often undertaken to try to prevent permanent visual loss. Excisional surgery is generally reserved for lesions unresponsive to medical therapy. Radiation therapy can be effective but is rarely used because of the risk of impaired bone growth and risk of induction of late malignancies.

Corticosteroids remain the mainstay of treatment for HOI. Other pharmacological agents such as interferon alfa may be efficacious, but have a greater potential for toxicity. ${ }^{23}$ Periorbital HOI can be treated with oral, topical, or intralesional corticosteroids. Each of the three modes of corticosteroid administration presents unique risks and benefits. Oral corticosteroids can be effective in preventing further haemangioma growth as well as accelerating involution of both superficial and deep haemangiomas, but its numerous potential side effects include cushingoid features, growth deceleration, irritability, personality changes, gastrointestinal upset, weight gain, adrenal suppression, increased susceptibility to infection, and hypertension. ${ }^{24-8}$ Frequency of systemic side effects from oral steroids has been documented in the general dermatological literature for treatment of nonperiorbital HOI. ${ }^{2}$ Local side effects include lid thickening. ${ }^{9}$

Intralesional injection may limit systemic exposures to corticosteroids, but complications include ophthalmic artery occlusion, retinal embolisation, and central retinal artery occlusion. ${ }^{10-13}$ Systemic side effects for intralesional injection include cushingoid features, growth deceleration, and adrenal suppression. ${ }^{14-18}$ Local side effects include eyelid hypopigmentation, subcutaneous fat atrophy, sclerodermiform linear atrophy, periocular calcification, and eyelid necrosis. ${ }^{16}{ }^{19-26}$

Topical corticosteroids can effectively induce involution in more superficial haemangiomas but appear to be less effective at reducing anisometropia and are unlikely to be effective for deeper haemangiomas. ${ }^{15}{ }^{27}$ Local side effects of long term topical corticosteroids include atrophy and hypopigmentation, and topical steroids may also raise intraocular pressure and cause posterior subcapsular cataracts. ${ }^{15} 28$

Despite a growing focus on evidence based practice throughout medicine, many common practices in ophthalmology are based on experienced recommendation rather than strong clinical evidence. Although intralesional steroid injections appear to be the most common modality of treatment for HOI, no randomised prospective trials exist for steroid treatment of periorbital HOI. ${ }^{29}$ Dosages for steroid injections are generally based on the original recommendations made by Kushner, ${ }^{30}$ while recommendations for oral and topical steroids are similarly based on small case series and user preferences. ${ }^{2}{ }^{31}$ Periorbital haemangiomas of infancy make up a small proportion of most paediatric ophthalmology practices and large cohort studies are therefore difficult to conduct. Despite decades of steroid treatment of haemangiomas by ophthalmologists, the literature consists primarily of case studies and small case series. This article aims to systematically evaluate the literature on steroid treatment of periorbital haemangiomas of infancy to determine the relative efficacy and complications of oral, topical, and intralesional corticosteroids.

Abbreviations: $\mathrm{HOI}$, haemangioma of infancy; $\mathrm{SE}$, spherical equivalent 
Table 1 Inclusion criteria

- Case series with at least five periorbital $\mathrm{HOI}$ patients treated with oral, intralesional, or topical corticosteroids

- Measurement or attempted measurement of at least one objective ophthalmological end point (refractive error/astigmatism, visual acuity, strabismus) both before and after treatment for the affected eye

- Corticosteroid duration and dosage documented

- Published in English with human subjects

\section{METHOD}

Searches were conducted in the National Library of Medicine's PubMed databse (from January 1970 through June 2003) as well as the Cochrane Library. Searches were conducted using keywords "haemangioma AND periorbital," "haemangioma AND periocular," and "haemangioma AND steroid." Titles and abstracts of all studies identified by electronic and hand searches were reviewed. All potentially eligible studies were retrieved in hard copy and reviewed for inclusion criteria (table 1).

Bibliographies were reviewed to locate further articles meeting inclusion criteria. Exclusion criteria (table 2) were applied to all resulting studies in order to create a subset with uniform diagnosis for quantitative systematic analysis.

Objective ophthalmological end points for inclusion were limited to refractive error, visual acuity, or strabismus. Haemangioma volume and surface area were not used because changes in those parameters do not necessarily directly reflect impingement on the visual axis and therefore may not reflect the lesion's impact on visual development. Cases of HOI with primarily intraorbital involvement or in which intraorbital versus extraorbital involvement was unclear were excluded because the extraorbital component could not be evaluated independently. These criteria were applied to specific cases within series, so that a subset of cases could be included if they passed criteria.

Data collected for subjects who met criteria included haemangioma location, type of steroid, dosage of steroid, refractive error before and after treatment, visual acuity before and after treatment, strabismus, occlusion therapy, length of follow up, steroid side effects, and complications of delivery.

\section{RESULTS}

Systematic review of the literature using the keywords above and bibliography searches revealed 360 references, of which 81 contained original reports of periorbital HOI cases treated with steroids. Review of these references revealed five case series with 41 patients meeting inclusion criteria. After applying exclusion criteria, 28 individual cases from four case series remained ${ }^{15} 193233$ (table 3 ).

Of the four cases that passed criteria, three contained refractive data for the unaffected eye both before and after treatment while the fourth (Morrell et al) included only pretreatment data for the unaffected eye. One series of five patients was treated with topical corticosteroids; the remaining patients were treated with intralesional steroid injections.

The largest study excluded was a review of 101 periorbital capillary haemangioma patients by Haik et al in 1979. ${ }^{9}$ Ten patients in that study were treated with oral corticosteroids, of which five also received external radiation therapy. Steroid dosage was not documented, and no objective ophthalmologic end points were published. A 1985 study by Kushner reviewed 25 periorbital HOI patients treated with injection corticosteroids. Although 21 patients showed a marked or moderate response based on estimated lesion size, the study lacked relevant ophthalmological end points.. ${ }^{34}$ Boyd and

\section{Table 2 Exclusion criteria}

Kasabach-Merritt syndrome

- Sturge-Weber syndrome

- Haemangioma of infancy incorrectly defined based on case descriptions

- Primarily or solely intraorbital involvement

- Location of haemangioma not documented

- Less than 6 months' follow up

Collin published a study in 1991 in which nine of 15 eyelid haemangioma patients responded to intralesional steroids as measured by the lesion's dimensions. ${ }^{35}$ The presence or absence of amblyopia was recorded post-treatment, but no ophthalmological end points were recorded before treatment. Willshaw and Deady published a study in 1987 with 13 periorbital capillary haemangioma patients treated with intralesional steroids, but without specifying intraorbital versus extraorbital involvement. ${ }^{36}$ Deady and Willshaw published a study in 1986 of 24 patients with periorbital haemangiomas, of whom nine were treated with intralesional steroids. ${ }^{37}$ Refractive error for a subset of patients was measured before treatment, but no objective end points were measured after treatment. A 1992 study by Assaf et al included 12 patients of whom 11 were treated with intralesional steroids and one with oral steroids. ${ }^{38}$ Both refractive error and visual acuity were measured before treatment, but no end points were measured after treatment. Stigmar et al published a study of 51 patients in 1978, but the number of patients treated with steroids was not specified. ${ }^{39}$

Several large case series of capillary haemangioma patients contained subsets of patients with facial lesions but either did not specify location (periorbital, intraorbital) or did not break down objective data by location..$^{4} 16$ 40-44

Of the cases that met inclusion criteria, five patients in one series were treated with topical steroids and 25 patients from three reports were treated with injected steroids. No patients treated with oral steroids met inclusion criteria for the study. Patients who received intralesional injections tended to demonstrate reduced astigmatism at follow up after treatment ( 19 of 23). Two out of five patients in the topical steroid series showed reduced astigmatism following treatment. Only one of five topically treated patients had reduced spherical equivalent refractive error after treatment, compared to 16 of 23 patients treated with intralesional steroids.

\section{Side effects and complications of steroid delivery}

Systemic side effects of corticosteroids for treatment of periorbital HOI have been documented for both intralesional and oral steroids. Side effects and complications of steroid delivery were not evaluated by inclusion or exclusion criteria since the vast majority of examples in the literature come from case reports or small series. No existing studies document frequency of side effects or complications of the various steroids.

\section{DISCUSSION}

The most striking result of our study is the very small number of patients whose treatment results could be evaluated objectively. Despite the use of corticosteroids in the treatment of haemangiomas for more than three decades and the high risk of morbidity leading to permanent visual loss, studies with measurable outcomes in this setting are lacking. In those case series which were evaluated, we found insufficient evidence to demonstrate benefits of one corticosteroid over another in patients with periorbital haemangioma of infancy. Similarly, we found insufficient evidence for increased side effects of one steroid over another. We found weak evidence 


\begin{tabular}{|c|c|c|c|c|c|c|c|c|}
\hline $\begin{array}{l}\text { Author, } \\
\text { year }\end{array}$ & $\begin{array}{l}\text { Subjects } \\
\text { (total) }\end{array}$ & Modality: dose* & $\begin{array}{l}\text { Refraction before } \\
\text { treatment }\end{array}$ & $\begin{array}{l}\text { SE before } \\
\text { treatment }\end{array}$ & $\begin{array}{l}\text { Refraction after } \\
\text { treatment }\end{array}$ & $\begin{array}{l}\text { SE after } \\
\text { treatment }\end{array}$ & $\begin{array}{l}\text { Age } \\
\text { (months) }\end{array}$ & $\begin{array}{l}\text { Following } \\
\text { (months) }\end{array}$ \\
\hline \multirow[t]{5}{*}{$\begin{array}{l}\text { Elsas }^{15} \\
1994\end{array}$} & \multirow[t]{5}{*}{$5(5)$} & Top: clobetasol $0.05 \%$ & $+2.00+3.00 \times 140$ & +3.50 & $+5.00+1.00 \times 20$ & +5.50 & 14 weeks & 60 \\
\hline & & Top: clobetasol $0.05 \%$ & $\begin{array}{l}+2.00 \mathrm{sph} \\
-1.50+1.00 \times 45 \\
+2.00+0.50 \times 135\end{array}$ & $\begin{array}{l}+2.00 \\
-1.00 \\
+2.25\end{array}$ & $\begin{array}{l}+0.75 \mathrm{sph} \\
+1.50+0.50 \times 120 \\
20 / 30\end{array}$ & $\begin{array}{l}+0.75 \\
+1.75\end{array}$ & 3 & 37 \\
\hline & & Top: clobetasol 0.05\% & $\begin{array}{l}+1.00 \mathrm{sph} \\
+1.00 \mathrm{sph}\end{array}$ & +1.00 & $\begin{array}{l}-5.75+3.00 \times 55 \\
+\mathbf{0 . 7 5}+0.75 \times \mathbf{4 5}\end{array}$ & $\begin{array}{l}-4.25 \\
+1.13\end{array}$ & 11 weeks & 38 \\
\hline & & Top: clobetasol $0.05 \%$, pred drops & $\begin{array}{l}+1.00 \mathrm{sph} \\
+1.00 \mathrm{sph}\end{array}$ & $\begin{array}{l}+1.00 \\
+1.00\end{array}$ & & $\begin{array}{l}-10.00 \\
-1.00\end{array}$ & 9 weeks & 20 \\
\hline & & Top: clobetasol $0.05 \%$, pred drops & $\begin{array}{l}-1.50+1.00 \times 135 \\
-1.00+0.50 \times 90\end{array}$ & $\begin{array}{l}-1.00 \\
-0.75\end{array}$ & $\begin{array}{l}-1.50+1.50 \times 145 \\
+1.00 \mathrm{sph}\end{array}$ & $\begin{array}{l}-0.75 \\
+1.00\end{array}$ & 11 weeks & 8 \\
\hline \multirow{5}{*}{$\begin{array}{l}\text { Kushner }^{33} \\
1982\end{array}$} & \multirow[t]{5}{*}{$5(10)$} & IL:I 12 mg/80 mg, 9 mg/6 mg & $+1.75+1.00 \times 180$ & +2.25 & $+1.75 \mathrm{sph}$ & +1.75 & 4 & 7 \\
\hline & & IL: 40 mg/6 mg ×2 & $\begin{array}{l}+1.00 \mathrm{sph} \\
\text { Plano }+3.50 \times 20 \\
+2.50+0.50 \times 135\end{array}$ & $\begin{array}{l}+1.00 \\
+1.75 \\
+2.75\end{array}$ & $\begin{array}{l}+1.50 \mathrm{sph} \\
-1.50+1.50 \times 80 \\
\text { Plano }\end{array}$ & $\begin{array}{l}+1.50 \\
-0.75 \\
\text { Plano }\end{array}$ & 3 & 13 \\
\hline & & IL: 40 mg/6 mg ×2 & $\begin{array}{l}+4.00+3.00 \times 10 \\
+3.00 \mathrm{sph}\end{array}$ & $\begin{array}{l}+5.50 \\
+3.00\end{array}$ & $\begin{array}{l}+0.50+1.00 \times 35 \\
+0.50 \mathrm{sph}\end{array}$ & $\begin{array}{l}+1.00 \\
+0.50\end{array}$ & 2 & 13 \\
\hline & & IL: 40 mg/6 mg ×2 & $\begin{array}{l}+1.00+2.50 \times 80 \\
+0.50 \mathrm{sph}\end{array}$ & $\begin{array}{l}+2.25 \\
+0.50\end{array}$ & $\begin{array}{l}+0.50+0.75 \times 80 \\
+0.50 \mathrm{sph}\end{array}$ & $\begin{array}{l}+0.87 \\
+0.50\end{array}$ & 10 & 6 \\
\hline & & IL: 6 mg betamethasone & $\begin{array}{l}+1.50 \mathrm{sph} \\
+1.50 \mathrm{sph}\end{array}$ & $\begin{array}{l}+1.50 \\
+1.50\end{array}$ & $\begin{array}{l}+1.50 \mathrm{sph} \\
+1.50 \mathrm{sph}\end{array}$ & $\begin{array}{l}+1.50 \\
+1.50\end{array}$ & 3 & 48 \\
\hline \multirow[t]{2}{*}{$\begin{array}{l}\text { Morrell19 } \\
1991\end{array}$} & \multirow[t]{2}{*}{$13(15)$} & \multirow[t]{2}{*}{ IL: $20-40 \mathrm{mg} / 4 \mathrm{mg}$, up to $4 \times$} & $-1.00+3.00 \times 110$ & +0.50 & $+1.50 \mathrm{sph}$ & +1.50 & 6 & 6 \\
\hline & & & $\begin{array}{l}+3.50+1.50 \times 155 \\
-0.25+0.75 \times 180 \\
-0.50+2.00 \times 180 \\
-2.00+2.50 \times 120 \\
+1.50+2.50 \times 125 \\
-2.00+3.25 \times 120 \\
+1.50+2.50 \times 125 \\
+0.50+0.75 \times 120 \\
+0.25+0.75 \times 80 \\
+5.00+2.00 \times 90 \\
+1.50+3.00 \times 90 \\
+0.50+1.50 \times 90\end{array}$ & $\begin{array}{l}+4.25 \\
+0.13 \\
+0.50 \\
-0.75 \\
+2.75 \\
-0.38 \\
+2.75 \\
+0.88 \\
+0.63 \\
+6.00 \\
+3.00 \\
+1.25\end{array}$ & $\begin{array}{l}+2.00 \mathrm{sph} \\
-0.75+0.50 \times 180 \\
\text { Plano+1.50 } \\
-0.75+2.25 \times 180 \\
+0.75 \mathrm{sph} \\
-2.00+3.25 \times 117 \\
+1.25+0.75 \times 175 \\
+0.75 \mathrm{sph} \\
\text { Plano+0.25 } \\
+2.00+1.00 \times 90 \\
+0.50+0.50 \times 90\end{array}$ & $\begin{array}{l}+2.00 \\
-0.50 \\
+0.75 \\
+0.38 \\
+0.75 \\
-0.38 \\
+1.63 \\
+0.75 \\
+0.13 \\
+3.63 \\
+2.50 \\
+0.75\end{array}$ & $\begin{array}{l}15 \\
3 \\
3 \\
12 \\
5 \\
14 \text { years } \\
5 \\
6 \\
6 \\
16 \\
5 \\
6\end{array}$ & $\begin{array}{l}46 \\
18 \\
12 \\
21 \\
24 \\
31 \\
10 \\
13 \\
10 \\
19 \\
6 \\
13\end{array}$ \\
\hline \multirow{2}{*}{$\begin{array}{l}\text { Motwani } i^{32} \\
1995\end{array}$} & \multirow[t]{2}{*}{$5(23)$} & \multirow[t]{2}{*}{ IL: $40 \mathrm{mg} / 6 \mathrm{mg}$ once } & $+2.00+1.00 \times 90$ & +2.50 & $+1.50 \mathrm{sph}$ & +1.50 & 4 & 49 \\
\hline & & & $\begin{array}{l}+2.25+0.25 \times 90 \\
+2.50+1.50 \times 90 \\
+3.00+0.50 \times 180 \\
-2.75+5.50 \times 10 \\
+1.00+1.75 \times 20 \\
+0.75+0.50 \times 90 \\
+0.75 \mathrm{sph} \\
+1.00+5.00 \times 135 \\
+2.50 \mathrm{sph}\end{array}$ & $\begin{array}{l}+2.38 \\
+3.25 \\
+3.25 \\
0.00 \\
+1.88 \\
+1.00 \\
+0.75 \\
+3.50 \\
+2.50\end{array}$ & $\begin{array}{l}+1.00 \mathrm{sph} \\
+0.75+1.25 \times 90 \\
+0.50+0.50 \times 90 \\
-3.75+3.00 \times 10 \\
-0.50+0.75 \times 160 \\
+1.00+1.00 \times 90 \\
+2.00 \mathrm{sph} \\
+1.50+2.00 \times 135\end{array}$ & $\begin{array}{l}+1.00 \\
+1.38 \\
+0.75 \\
-2.25 \\
-0.13 \\
+1.50 \\
+2.00 \\
+2.50\end{array}$ & $\begin{array}{l}1.5 \\
2\end{array}$ & $\begin{array}{l}65 \\
32 \\
78\end{array}$ \\
\hline
\end{tabular}

*Dosages for combination steroid injections are listed as triamcinolone $(\mathrm{mg})$ followed by betamethasone $(\mathrm{mg})$ unless otherwise specified. $\mathrm{SE}$, spherical equivalent; Top = topical, IL = intralesional. Values in bold are for the unaffected eye, when available.

that intralesional steroid injections may result in reduced refractive error.

The five cases involving topical steroids generally demonstrated worse spherical equivalent refractive error after treatment, with no clear trend in the astigmatic component alone. The 23 cases involving intralesional injection demonstrated a trend towards reduced astigmatism and reduced spherical equivalent refractive error with treatment. Although one might argue that steroids speeded up involution, the improvement in refractive error cannot be attributed to steroid treatment rather than the natural course of development after spontaneous haemangioma involution. The Motwani series included four patients who were managed conservatively (without steroids, not included in table 3). The authors concluded that visual outcomes were similar in treated and untreated patients, but selection of patients was non-randomised.

Despite reports of successful steroid treatment of periorbital HOI dating back to the 1970s, the evidence for relative efficacy and safety of oral, topical, and intralesional steroids remains scant. Several of the largest studies produced in our literature search were not included in this review because they did not measure objective ophthalmological data before and after treatment. The largest single study meeting criteria, by Morrell and Willshaw, contained only 13 patients with measured objective end points both before and after treatment. ${ }^{19}$

The complications of untreated periorbital HOI have been well documented, including astigmatism, myopia, amblyopia, and strabismus. Several articles have reported on the beneficial effect of corticosteroids in preventing or reducing occlusion of the visual axis. However, a substantial proportion of these studies and case series has failed to document refractive error or visual acuity before and after treatment. Several studies developed customised grading systems in order to stratify patient responses to steroids. In most cases, the grading systems were either subjective or based on data such as change in lesional size, which may or may not cause an objective improvement in visual outcome. Corticosteroids may facilitate haemangioma involution and thereby decrease volume or surface area of the lesion. However, changes in volume or surface area are only relevant to the extent that the haemangioma impinges on the visual axis at some point and involution results in clearing of the axis. Oral steroid 
treatment has been show to produce a response in cutaneous haemangiomas as measured by surface area, but the goals of ophthalmological treatment differ, at least in part, from the goals of dermatological treatment of HOI. ${ }^{8}$

Because of the limited numbers of cases meeting our inclusion criteria and the variation in dosage and administration of corticosteroids given, the results are not conducive to a statistical meta-analysis. Since there were no studies comparing different modalities of steroid therapy and no studies of individual modalities large enough to estimate efficacy, no conclusions can be drawn regarding which modality is most efficacious. The studies reviewed indicate that intralesional injections appear efficacious insofar as they may reduce astigmatism and spherical equivalents of refractive error; the efficacy of topical steroids is less clear. However, greater numbers of patients in each group are needed to project an estimate of overall efficacy. A larger study might also clarify how much of observed reduction in refractive error is the result of correction with ageing or the natural course of haemangioma involution as opposed to steroid treatment effects.

Similarly, there are insufficient data to estimate the incidence of corticosteroid side effects for patients treated with steroids for periorbital HOI or complications of intralesional injections in particular. Numerous case reports have established the need for caution in giving prolonged courses of steroids and the need for precautions to avoid vascular occlusion when injecting intralesional steroids, but the incidence of such complications remains unknown.

A useful determination of relative efficacy and side effects of different steroid modalities for treatment of periorbital HOI could be achieved through a prospective, longitudinal multicentre trial. Objective measurements such as visual acuity, astigmatism, or strabismus must be measured both before and after treatment, with follow up more than 6 months after completion of treatment and concurrent measurements in the unaffected eye. We would recommend checking cycloplegic refractions monthly until stabilisation of haemangioma growth, with subsequent bimonthly and then quarterly checks for 3 years. Visual acuity can be measured by preferential looking, and standardised protocols of occlusion therapy can be used for treatment of amblyopia. Steroid preparations and dosages must also be standardised.

In an era of evidence based medicine, corticosteroid treatment of periorbital HOI is still based primarily on recommendations made decades ago as well as the personal preferences of the treating paediatric ophthalmologist. The need for objective data to guide future practices is evident, and establishing the relative efficacy and safety of oral, topical and intralesional steroids through a randomised prospective study would greatly benefit those children with periorbital HOI requiring ophthalmological intervention.

\section{Authors' affiliations}

T M Ranchod, Santa Clara Valley Medical Center, San Jose, CA, USA I J Frieden, Department of Dermatology and Pediatrics, University of California, San Francisco, CA, USA

D R Fredrick, Department of Ophthalmology, University of California, San Francisco, CA, USA

No financial support was provided for this work and the authors claim no competing interests.

Competing interests: none declared

\section{REFERENCES}

1 Chiller KG, Passaro D, Frieden IJ. Hemangiomas of infancy:clinical characteristics, morphologic subtypes, and their relationship to race, ethnicity, and sex. Arch Dermatol 2002;138:1567-76.

2 Bruckner AL, Frieden IJ. Hemangiomas of infancy. J Am Acad Dermatol 2003;48:477-93; quiz 494-6.
3 Barlow CF, Priebe CJ, Mulliken JB, et al. Spastic diplegia as a complication of interferon alfa-2a treatment of hemangiomas of infancy. J Pediatr 1998; 132:527-30.

4 Weber TR, Connors RH, Tracy TF Jr, et al. Complex hemangiomas of infants and children. Individualized management in 22 cases. Arch Surg 1990;125:1017-20; discussion 1020-1.

5 Bergstrom K, Enoksson P, Gamstorp I, et al. Haemangio-endothelioma of the orbit. Ophthalmologica 1978;177:115-20.

6 Nelson L. Intralesional corticosteroid injection for infantile hemangiomas of the eyelid. Pediatrics 1984;74:241-5.

7 Steahly LP, Almquist HT. Steroid treatment of an orbital or periocular hemangioma. J Pediatr Ophthalmol 1977;14:35-7.

8 Bennett ML, Fleischer AB Jr, Chamlin SL, et al. Oral corticosteroid use is effective for cutaneous hemangiomas: an evidence-based evaluation. Arch Dermatol 2001;137:1208-13.

9 Haik BG, Jakobiec FA, Ellsworth RM, et al. Capillary hemangioma of the lids and orbit: an analysis of the clinical features and therapeutic results in 101 cases. Ophthalmology 1979;86:760-92.

10 Walker RS, Custer PL, Nerad JA. Surgical excision of periorbital capillary hemangiomas. Ophthalmology 1994; 101:1333-40.

11 Egbert JE, Schwartz GS, Walsh AW. Diagnosis and treatment of an ophthalmic artery occlusion during an intralesional injection of corticosteroid into an eyelid capillary hemangioma. Am J Ophthalmol 1996;121:638-42.

12 Kushner BJ, Lemke BN. Bilateral retinal embolization associated with intralesional corticosteroid injection for capillary hemangioma of infancy. J Pediatr Ophthalmol Strabismus 1993:30:397-9.

13 Shorr N, Seiff SR. Central retinal artery occlusion associated with periocular corticosteroid injection for juvenile hemangioma. Ophthalmic Surg 1986;17:229-31.

14 Ruttum MS, Abrams GW, Harris GJ, et al. Bilateral retinal embolization associated with intralesional corticosteroid injection for capillary hemangioma of infancy. J Pediatr Ophthalmol Strabismus 1993;30:4-7.

15 Elsas FJ, Lewis AR. Topical treatment of periocular capillary hemangioma. J Pediatr Ophthalmol Strabismus 1994;31:153-6.

16 Chowdri NA, Darzi MA, Fazili Z, et al. Intralesional corticosteroid therapy for childhood cutaneous hemangiomas. Ann Plast Surg 1994;33:46-51.

17 Glatt HJ, Putterman AM, Van Aalst JJ, et al. Adrenal suppression and growth retardation after injection of periocular capillary hemangioma with corticosteroids. Ophthalmic Surg 1991;22:95-7.

18 Weiss AH. Adrenal suppression after corticosteroid injection of periocular hemangiomas. Am J Ophthalmol 1989;107:518-22.

19 Morrell AJ, Willshaw HE. Normalisation of refractive error after steroid injection for adnexal haemangiomas. Br J Ophthalmol 1991;75:301-5.

20 Cogen MS, Elsas FJ. Eyelid depigmentation following corticosteroid injection for infantile ocular adnexal hemangioma. J Pediatr Ophthalmol Strabismus 1989;26:35-8.

21 Droste PJ, Ellis FD, Sondhi N, et al. Linear subcutaneous fat atrophy after corticosteroid injection of periocular hemangiomas. Am J Ophthalmol 1988; 105:65-9.

22 Ford MD, Codere F. Perilymphatic subcutaneous atrophy in adnexal hemangioma: a complication of intralesional corticosteroid injection. Ophthalmic Surg 1990;21:215-7.

23 Townshend LM, Buckley EG. Linear subcutaneous fat atrophy after a single corticosteroid injection for ocular adnexal hemangioma. Am J Ophthalmol 1990; 109:102-3.

24 Vazquez-Botet R, Reyes BA, Vazquez-Botet M. Sclerodermiform linear atrophy after the use of intralesional steroids for periorbital hemangiomas: a review of complications. J Pediatr Ophthalmol Strabismus 1989;26:124-7.

25 Carruthers J, Jevon G, Prendiville J. Localized dystrophic periocular calcification: a complication of intralesional corticosteroid therapy for infantile periocular hemangiomas. Pediatr Dermatol 1998;15:23-6.

26 Sutula FC, Glover AT. Eyelid necrosis following intralesional corticosteroid injection for capillary hemangioma. Ophthalmic Surg 1987; 18:103-5.

27 Cruz OA, Zarnegar SR, Myers SE. Treatment of periocular capillary hemangioma with topical clobetasol propionate. Ophthalmology 1995; 102:2012-5.

28 Carnahan MC, Goldstein DA. Ocular complications of topical, peri-ocular, and systemic corticosteroids. Curr Opin Ophthalmol 2000;1 1:478-83.

29 Wasserman BN, Medow NB, Homa-Palladino M, et al. Treatment of periocular capillary hemangiomas. J AAPOS 2004;8:175-81.

30 Kushner BJ. Capillary hemangiomas of the adnexa in infants. In: Hornblass, eds. Oculoplastic, orbital, and reconstructive surgery. Baltimore: Williams and Wilkins, 1988:243-250

31 Coats DK, O'Neil JW, D'Elia VJ, et al. SubTenon's infusion of steroids for treatment of orbital hemangiomas. Ophthalmology 2003;1 10:1255-9.

32 Kushner BJ. Intralesional corticosteroid injection for infantile adnexal hemangioma. Am J Ophthalmol 1982;93:496-506.

33 Motwani MV, Simon JW, Pickering JD, et al. Steroid injection versus conservative treatment of anisometropia amblyopia in juvenile adnexal hemangioma. J Pediatr Ophthalmol Strabismus 1995;32:26-8.

34 Kushner BJ. The treatment of periorbital infantile hemangioma with intralesional corticosteroid. Plast Reconstr Surg 1985;76:517-26.

35 Boyd MJ, Collin JR. Capillary haemangiomas: an approach to their management. Br J Ophthalmol 1991;75:298-300.

36 Willshaw HE, Deady JP. Vascular hamartomas in childhood. J Pediatr Surg 1987;22:281-3.

37 Deady JP, Willshaw HE. Vascular hamartomas in childhood. Trans Ophthalmol Soc UK 1986;105:712-16.

38 Assaf A, Nasr A, Johnson T. Corticosteroids in the management of adnexal hemangiomas in infancy and childhood. Ann Ophthalmol 1992;24:12-18. 
39 Stigmar G Crawford JS, Ward CM, et al. Ophthalmic sequelae of infantile hemangiomas of the eyelids and orbit. Am J Ophthalmol 1978;85:806-13.

40 Burstein FD, Simms C, Cohen SR, et al. Intralesional laser therapy of extensive hemangiomas in 100 consecutive pediatric patients. Ann Plast Surg 2000;44:188-94

41 Gangopadhyay AN, Sharma SP, Gopal SC, et al. Local steroid therapy in cutaneous hemangiomas. Indian Pediatr 1996;33:31-3.
42 Pongprasit P. Corticosteroid treatment of extensive hemangiomas: analysis of 22 cases in children. J Med Assoc Thai 1992;75:671-9.

43 Sadan N, Wolach B. Treatment of hemangiomas of infants with high doses of prednisone. J Pediatr 1996;128:141-6.

44 Sharma LK, Dalal SS. Corticosteroid therapy in the treatment of cutaneous hemangioma of infancy and childhood. Indian J Pediatr 1983;50:153-6.

\section{Clinical Evidence-Call for contributors}

Clinical Evidence is a regularly updated evidence-based journal available worldwide both as a paper version and on the internet. Clinical Evidence needs to recruit a number of new contributors. Contributors are healthcare professionals or epidemiologists with experience in evidence-based medicine and the ability to write in a concise and structured way.

Areas for which we are currently seeking authors:

- Child health: nocturnal enuresis

- Eye disorders: bacterial conjunctivitis

- Male health: prostate cancer (metastatic)

- Women's health: pre-menstrual syndrome; pyelonephritis in non-pregnant women

However, we are always looking for others, so do not let this list discourage you.

Being a contributor involves:

- Selecting from a validated, screened search (performed by in-house Information Specialists) epidemiologically sound studies for inclusion.

- Documenting your decisions about which studies to include on an inclusion and exclusion form, which we keep on file.

- Writing the text to a highly structured template (about 1500-3000 words), using evidence from the final studies chosen, within 8-10 weeks of receiving the literature search.

- Working with Clinical Evidence editors to ensure that the final text meets epidemiological and style standards.

- Updating the text every six months using any new, sound evidence that becomes available. The Clinical Evidence in-house team will conduct the searches for contributors; your task is simply to filter out high quality studies and incorporate them in the existing text.

- To expand the topic to include a new question about once every 12-18 months.

If you would like to become a contributor for Clinical Evidence or require more information about what this involves please send your contact details and a copy of your CV, clearly stating the clinical area you are interested in, to Klara Brunnhuber (kbrunnhuber@ bmigroup.com).

\section{Call for peer reviewers}

Clinical Evidence also needs to recruit a number of new peer reviewers specifically with an interest in the clinical areas stated above, and also others related to general practice. Peer reviewers are healthcare professionals or epidemiologists with experience in evidence-based medicine. As a peer reviewer you would be asked for your views on the clinical relevance, validity, and accessibility of specific topics within the journal, and their usefulness to the intended audience (international generalists and healthcare professionals, possibly with limited statistical knowledge). Topics are usually 1500-3000 words in length and we would ask you to review between 2-5 topics per year. The peer review process takes place throughout the year, and our turnaround time for each review is ideally 10-14 days.

If you are interested in becoming a peer reviewer for Clinical Evidence, please complete the peer review questionnaire at www. clinicalevidence.com or contact Klara Brunnhuber (kbrunnhuber@bmjgroup.com). 